\title{
Computational Design Thinking and Controlled Transformations, for the schematic design of a second- year, multi-unit housing design studio
}

XXIV International Conference

of the Iberoamerican Society

of Digital Graphics

Medellin | Colombia

\author{
Simos Vamvakidis \\ Plymouth University | United Kingdom | yerasimo@gmail.com
}

\begin{abstract}
In previous phases of this research, a design method of physical \& digital modelling named Controlled Transformations was explored and evaluated with first-year architecture students, as a way to introduce students and architects to Computational Design Thinking, before using any parametric software. The paper briefly summarises the previous phases of this research, and highlights the key theoretical points which are then translated to the design method. It then extends and examines the application of the method, to teaching more complex, second- or third-year design studios. More specifically, it examines the application of this method for the design of a multi-unit housing project.
\end{abstract}

Keywords: Analogue Computational Design Thinking; Transformations; Design method; Second-year design studio; Multi-unit housing.

\section{INTRODUCTION}

Digital design tools are changing the way we teach, design and think of architecture, even if we never choose to use any software, as Oxman (2017), amongst many others, suggests. Students get exposed to digital software on their own, even if that software is not part of a design studio curriculum. A common outcome / problem of this fact is that students end up using software as mere representational tools, and not as a tools for synthesis.

In the approach discussed here, digital and parametric design tools are used as part of the design process (Computation) and not as mere representational tools (Computerisation), (Terzidis, 2006).

Architectural Synthesis, an often pain-stacking process in the first years of architectural studies, could potentially be supported by the discussed method.

The paper aims to contribute to research on design methods that will acquaint / introduce practitioners and students with no prior knowledge of parametric software (or digital design tools), with this realm of architectural design for the design of a multi-unit housing project.

In previous phases of this research, a design method of physical and digital modelling named Controlled Transformations was explored and evaluated with first-year architecture students.

The method was characterized as a "handmade" or an "analogue" Computational Design approach, drawing inspiration from the ongoing digital architectural design theory and digital design tools / software we use as architects. The method introduced ways to manipulate physical form and digital models and create multiple iterations / variations, almost the same way that parametric design software functions.
This paper summarises the previous phases of this research. It then highlights the key theoretical points which are then translated to the Controlled Transformations method.

It extends and examines the application of the method, from teaching first-year design studios, to teaching more complex, second- or third-year design studios.

More specifically, the current phase of this research examines the application of this method for the design of a multi-unit housing project in the first semester of the second year in a university in the UK.

\section{RELEVANT PEDAGOGICAL EXAMPLES}

In reference to digital architectural design pedagogy, there are already examples of using both digital and physical modelling iterations methods within the final year design studios of undergraduate architectural studies, such as the ones described in the textbook Generative Design (Agkathidis, 2015). This paper relates to this research, as it focuses on diagrams and the connection of physical and digital modelling in a design process.

The proposed approach also differs in a very clear way, as it begins with a first phase of solely physical modeling and diagrams that clearly map-out the design process in numbered transformation steps (while including the instructions) in a cyclical design process. It aims to add to the approach discussed by Agkathidis (2015), as it is applied in teaching quite soon, at the second year of architectural studies, prior to using any parametric software.

Existing examples of multi-unit housing projects in postgraduate studies which are fully designed using parametric software, arediscussed in the book Adaptive 
Ecologies, Correlated Systems of Living (Spyropoulos, 2013).

In Adaptive Ecologies, advanced parametric modelling skills were used by students already acquainted with digital design tools. The design method was based on manipulation of form for the Morphogenesis of multi-unit housing student projects. The Controlled Transformations method can be applied in undergraduate studies as it requires no knowledge of parametric design tools, even though it refers to Computational Design Thinking.

At the same time, the proposed method focuses on defining and testing relationships between the three fundamental programmatic areas found in any multi-unit housing project: Units, Circulation and Communal spaces.

It is using these traditional, fundamental programmatic areas, in order to produce a number of possible design variations, aiming to provide a pathway that could be used by any student or even traditional design office, as part of the schematic design process.

\section{SUMMARY OF PREVIOUS PHASES}

\section{SUMMARY OF KEY THEORETICAL POINTS}

The main theoretical points of a Computational Design approach Thinking approach have been discussed by Menges (2009), amongst others.

These points are translated into a design method that directly refers to digital design tools / software we use as architects.

The method introduces ways to manipulate physical form, almost the same way that digital design software manipulates digital models.

The Computational Design theory is still evolving and is inspired by other scientific fields. The key points have being discussed extensively in the previous phases of the this research (Vamvakidis, 2016, 2019)

Briefly mentioned, those fileds include biology and Thompson (1917) and his life-long research on the origin of the form of different, yet formally alike animal species. Which he documented with graphs of their form using a grid.

Maybe the most important field that affected the Computational Design Thinking approach is Cybernetics. Wiener (1961) and Pask (1969) created a theory where scientists, designers and software engineers used a newly found tool, namely digital technology, in order to design systems of interacting elements (elements from geometries to data), instead of designing mere objects.

More recently, technological fields that use digital animation media and software became a source of inspiration for the creation of form. Academics and architects such as Lynn (1999) discuss how an animated form that constantly changes shape, is what the architect is called to design. And a proposed project is merely an instant, a "freeze frame" of an ever-changing animation.
In a Computational Design approach, the diagram, as Eisenman (2009) / Van Berkel (2006) discuss, is the most fundamental design tool to document in an abstract, yet simple and clear way, specific and highlated information regarding a design project.

According to Vamvakidis $(2016,2019)$, the above key theoretical key points of Computational Design could be translated to the following explicit design method guidelines:

1.Using transformations in order to manipulate space.

2.Mapping any steps in a design process.

3.Adding feedback in a process that is cyclical.

4.Using the diagram in order to map the design process.

5.Including the instructions of the process itself.

6.Creating a CAD - CAM convergence.

\section{SUMMARY OF PREVIOUS DESIGN PHASES}

In the two previous phases of this research, a gradient transition from physical modelling (Phase 1/ semester 1), to digital and physical modelling (Phase 2 / semester 2), is followed for teaching the main design studio module, during the first academic year in architecture.

During Phase 1, three workshops of geometric transformations were introduced. In these workshops, students had to physically transform three specific initial geometries (a Cube, a Surface and a Curve).

Phase 1 focused on transformations of physical models as a way to map the design process in a controlled way, the same way any visual parametric software creates a map of interconnected design parameters that control / manipulate geometries.

Phase 2 of this research, focused on solely digital transformations in order to create architectural space; using a software used broadly for form-finding: Rhinoceros

It was important to have the same "target group" for both Phases (the same cohort of students) in order to test and evaluate their progression into Computational Design Thinking.

Phase 2 used the same key design points as Phase 1 . (Using geometric transformations and mapping the four design steps and instructions, in a cyclical design process where feedback is added to each of the design steps). This time, the initial geometry was either a sphere or a control point curve.

A series of transformation diagrams, digital and physical models were produced throughout Phase 2, the same way diagrams and physical models where produced in Phase 1 




Figure 1: Previous phases (Sigradi 2019): Schematic summary of outcomes. Mapping the design process / including the instructions.

Both phases were informed with the relevant theoretical background. Precedent design examples were presented to the students throughout the whole academic year before each workshop, both in Phase 1 and Phase 2, as well as relevant digital design theories.

\section{CURRENT PHASE METHODOLOGY}

The current phase takes the Controlled Transformations method a step further, using it for the design of a more complex project: a multi-unit housing project in the second year of architectural studies.

The main focus is to use the six design method guidelines stated above (Transformations, Design Steps, Instructions, Feddback,etc) for the design of the project. The method is applied in 4 weeks, the exact steps / procedures used throughout the semester are:

Week 1: Controlled Transformations lecture / workshop. Connecting physical to "analogue" digital modelling, while mapping the design process. Generic physical and digital transformations of Cubes, Surfaces, Curves and Spheres.

At the beginning of the design studio module, students are introduced to the Controlled Transformations method and the Computational Design Theory, through a studio lecture and workshop on geometric transformations with diagrams and phyical models, as discussed in Phase 1.
Week 2: Multi-unit housing precedents lecture / workshop. Understanding combinations / variations between Units, Circulation and Communal Spaces. Diagrams and physical I digital models that have different spatial qualities between these three programmatic areas.

On the second week, a lecture on globally aknowledged existing precedents, from Unite d'Habitation by Le Corbusier, to contemporary examples such as House 8 by BIG (Figure 2), introduces students to the three main programmatic areas that have to be combined in almost every multi-unit housing project:

(a) Housing Units, (b) Circulation and (c) Communal Spaces.

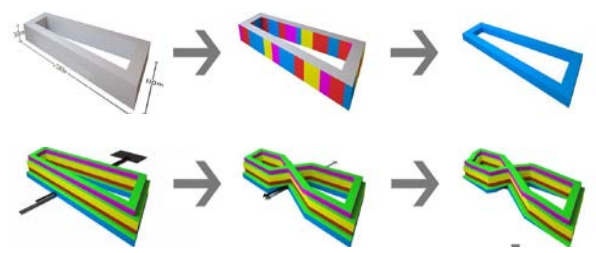

Figure 2: Initial design diagrams for House 8 by BIG.

A workshop takes place on the same day, where students create diagrams and very small, palm-sized, physical models that demonstrate the way units, circulation and communal spaces are combined in each precedent.

Week 3: Site visit and initial generic transformations for each student project. From physical to digital transformations, in a cyclical design process.

During week 3 lecture and workshop, students are explained that while using the Controlled Transformations method, and depending on the initial geometry they choose, as well at the initial programmatic area they choose (Units, Circulation or Communal Spaces), different prossible outcomes and iterations can be produced (Figure 3).

During weeks 3 and 4 , students are asked to produce their own initial generic transformation diagrams and palm-sized physical models, before taking the site conditions in full consideration. They could start with either physical or digital modelling, depending on whatever tool they were more confident with. But after the first day of modelling, they had to continue with both physical and digital models.

This allows them to focus on the relationships between programmatic areas, as well as geometric transformation parameters, rather than their modelling skills.

Week 5 -end of the semester: Further exploration of design scheme. From schematic design to final proposal. 


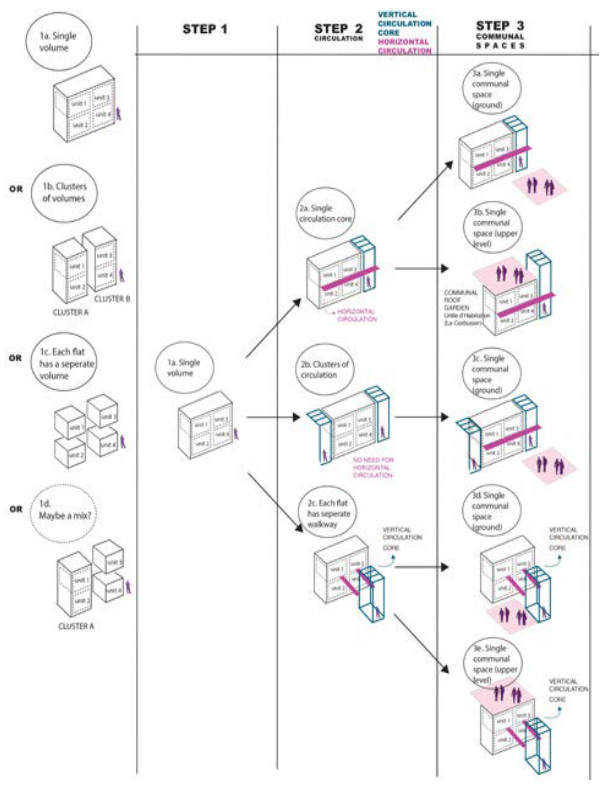

Figure 3: Variations / iterations for Unit configurations ( $1^{\mathrm{a}} / 1 \mathrm{~b}$ etc Step 1), followed by different possible Circulations (Step 2) and variable outcomes when addling Communal Spaces (Step 3) (image by the author).

Like in the previous phases of the Controlled Transformations method, students are asked to initially "manually" compose a System of Iterations, as Alexander (1968) discusses, rather than a single object, following the beforementioned design rules :

1.Use transformations in order to manipulate space.

2.Map and number the steps in their design process.

3.Add feedback in a process that is cyclical, returning to a previous step in order to iterate their design.

4.Use the diagram in order to map the design process.

5.Include the instructions of the process itself (the "commands" used to manipulate form).

6.Create a CAD - CAM convergence.

\section{RESULTS}

During week 3 and 4 of the semester students applied the Controlled Transformations method in a cyclical design process, and produced step-by-step diagrams of their "manual" digital model transformations, almost like parametric software like Grasshopper for Rhinoceros does.

They also had to document the process instructions, as Menges (2011) proposes.

The diagrams were variations regarding the spatial relationships between Units, Circulation and Communal Spaces. Students were no tlimited to a specific software, as long as they followed the design method guidelines stated above (Figures 4,5).
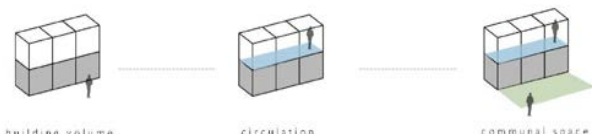

Option1

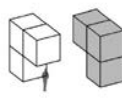

Guster of volumes

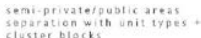

building volume
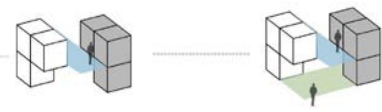

Option 2
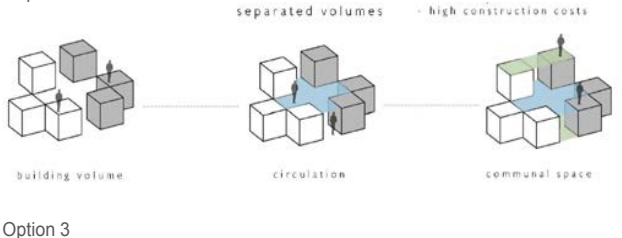

Option 3
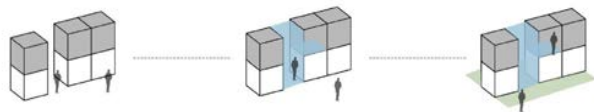

building yolume

circulation

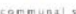

Option 4

Figure 4: "Analogue" or manual variations / iterations. Starting with 4 options for Units (Step1), adding Circulation (Step2) and adding Communal Spaces (Step3). Student: Ryan Barribal.
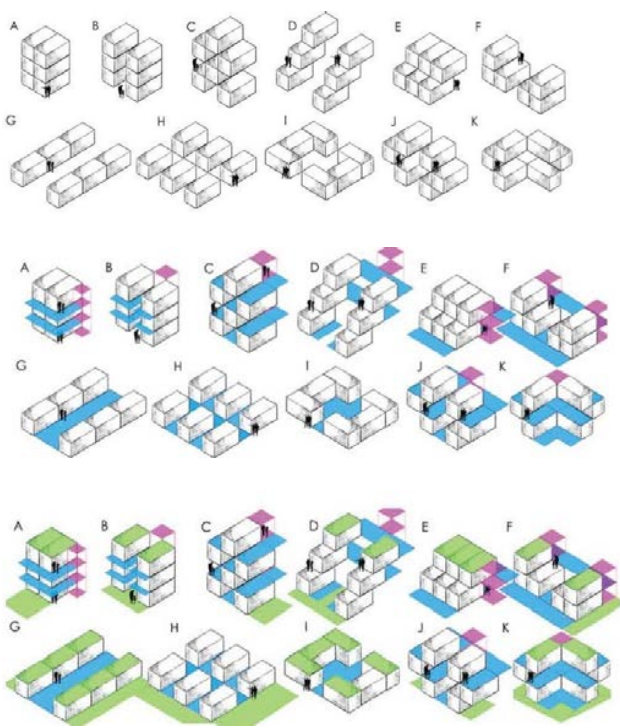

Figure 5: "Analogue" or manual variations / iterations. Starting with 11 options for Units (Step1), adding horizontal (cyan colour) and vertical (magenta) Circulation (Step2) and adding Communal Spaces (Step3). Student: Sebastian Ulloa-Thompson 
After exploring spatial relationships between only a few units, circulation and communal spaces, students experimented with aggregations of larger numbers of units. Which means that after setting their own "rules", they could apply those, for any number of units. Transformations such as pitched roofs that relate to context were also added in the design steps (Figure 6).



Step 1: Starting with cubic Unit

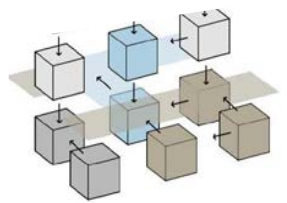

Step 2: Aggregating Units. (Grey and dark grey colour). Adding Communal spaces (cyan)

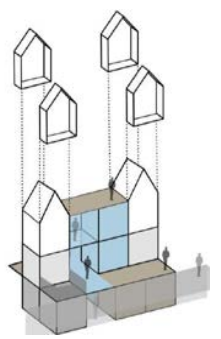

Step 3: Adding Circulation, transforming cubes for top floor

Figure 6: Starting with Units (Step1 - commmands: Copy / paste). Adding Communal Spaces (Step2 - command: Cube). Finally adding top floor Units with pitched roof (Step 3- command: Line, Extrude line). Student: Ryan Barribal.

Other students chose to start with Circulation, and then add Units and Communal Spaces (Figure 7).



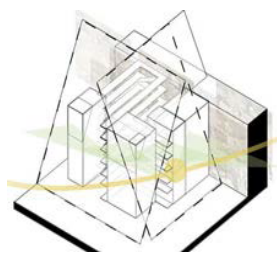
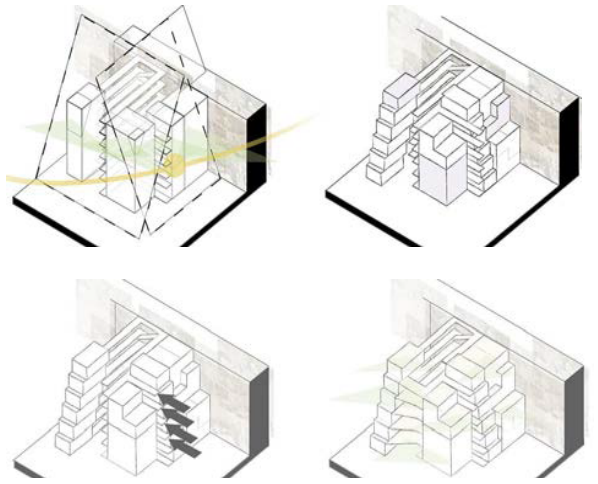

Figure 7: Starting with Circulation (Step1) commmands: Copy paste / scale. Adding Units (Step2) commands: Box. Finally adding Communal Spaces (Step 3) commands: Rectangle. Student: Kamil Perzanowski.

In order to reconnect digital with physical, students had to make physical models for their transformation diagrams. Making handmade models allowed them to test their design aesthetically, spatially and structurally.

Making final physical models after their sketch design steps models, allowed them to transform their design even further, from adding openings such as doors and windows, to materiality, such as opaque and translucent surfaces.
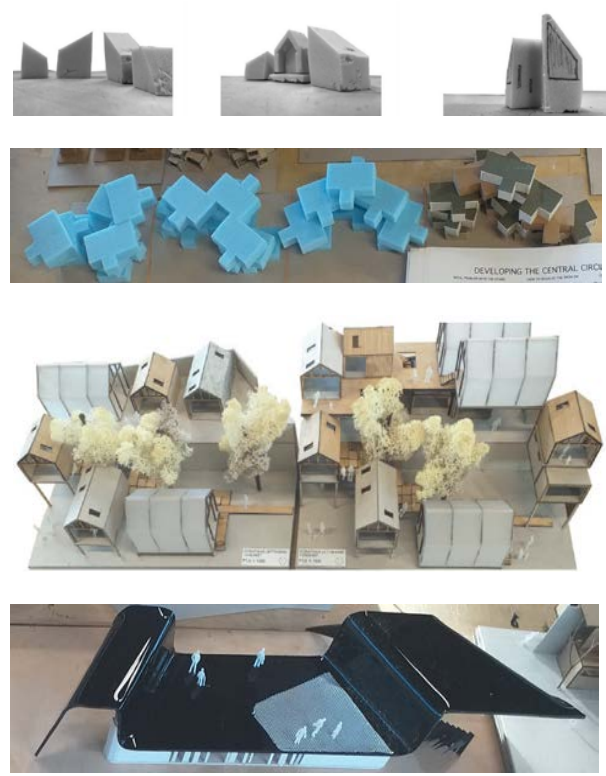

Figure 8: Sketch physical model iterations exploring possible spatial qualities between Units, Circulation and Communal spaces. Final project physical models with context and openings / materiality added. Students (from top to bottom): Ryan Barribal, Elie Savage, Jonathan Lettmann, Ben Giles. 


\section{DISCUSSION}

This paper discusses a method of teaching a second-year design studio for a multi-unit housing project, following a Computational Design Thinking approach. In any Computational approach, it is quite useful to initially specify the main geometries that will be transformed. In this paper, maybe like any schematic design approach, the main programmatic areas, such as Units, Circulation and Communal Spaces, become the main three geometries that are "manually" transformed. Manipulating physical or digital models was conducted while following the six design guidelines gave the students the chance to map-out their design process and have a more clear understanding of the spatial implications due to their design choices. It also gave them the chance to go back to a previous step and iterate their design. In a traditonal, intuitive approach, students often loose control of their design process, with all the frustrations that might lead to. Students had a clear perception of Computational Strategies, since theory and design were explicitly connected, during the week 1 relevant lecture, where all key theoretical points, from biology and Thompson (1917) to today, were discussed and translated to the design guidelines of the Controlled Transformations method.On week 3 , the exchange between physical and digital modelling for their geometric transformations allowed students to discuss the spatial qualities created in each design step. The fact that almost each diagram had to be materialised as a fast, small, palmsized physical model made out of foam (for volumes) or card (for surfaces) (and vice versa) also gave students the chance to discuss the aethetic and structural / materiality potential of each project. And helped students understand that digital models can imply materiality, depending on the element those surfaces create; for example a box or a thin surface.

"Accidents" that happened during modelling would also create chances for experimenting with "unintended" design steps. For example, in a physical model, an accident of having a corridor surface slicing too much through a foam box. And then having to modelling it digitally. Or accidentally moving a corridor surface too much inside a box volume in a digital model, and then testing it with a small sketch physical model. In a cyclical design process, the Controlled Transformations method gave students the chance to go back to a previous step and iterate even further their geometry, moving from generic transformations, to context-based transformations. The context- based factors included views, public access or environmental factors, such as the sun path. Since this is a second-year design studio module for a course that is accredited by RIBA and ARB, it was imperative to teach design in a way that the final project proposals take into consideration stuctural, environmental and materiality matters.

Considering the environmental parameters in their design process manually, (for example having a wire and a foam ball as the sun, or moving a lamp above a model), students are subtly prepared for parametric environmental plug-ins for Grasshopper, such as Ladybug. What Ladybug does automatically, students had to do "manually", so that they can understand how the sun path would eventually affect their design proposal.

\section{FURTHER DEVELOPMENT}

After experimenting with the discussed method and physical / digital modelling, on week 5, students could be introduced to Grasshopper plug-in for Rhino, during a week-long workshop, as a way to create a transition / connection, from the "analogue" digital realm and the "handmade" transformations, to the fully parametric digital realm. The same three programmatic areas would be represented with three different geometries. Grasshopper could be used initially to create a number of iterations for the combination of (a) Housing Units, (b) Circulation and (c) Communal spaces. This way the digital design tools could be used as a way to design (from the very initial schematic design stage)and not merely represent a preconcieved project. Computational Design Thinking lectures could be combined with multi-unit housing project lectures, each of which could be followed by a week of parametric modelling workshops, as well as a CAD/CAM convergence that constantly informs the design process (Kolarevic, 2009). During this process they would also produce CAM physical models (what they did manually before), which would then re-inform their design in a cyclical design process.

\section{REFERENCES}

Alexander, C. (1968). Systems generating systems, AD, 7(6), 605610.

Eisenman P. (1999). Diagram Diaries, London: Thames \& Hudson.

Lynn G. (1999). Animate Form, Princeton: Princeton Architectural Press.

Menges, A., Ahlquist, S. (2011). Computational Design Thinking, London: John Wiley \& Sons Ltd.

Oxman, R. (2017). Thinking difference: Theories and models of parametric design thinking, Design Studies vol 52 (1), 4-39. Retrieved from: https://isiarticles.com/bundles/Article/pre/pdf/148422.pdf

Oxman, R. (2008). Digital architecture as a challenge for design pedagogy: theory, knowledge,models and medium, Design Studies vol 29 (2), 99-117.

Pask, G. (1969). The Architectural Relevance of Cybernetics, AD, No 7/6, 494-496

Spyropoulos, T. (2013). Adaptive Ecologies. Correlated Systems of Living , London: AA Publications.

Terzidis, K. (2006), Algorithmic Design, London: Routledge.

Thompson, D. (1917). On Growth and Form, Cambridge: Cambridge University Press.

Vamvakidis, S. (2016). Controlled Transformations: A method to introduce first year architecture students to digital and parametric design thinking. Proceedings of the 20th Conference of the Iberoamerican Society of Digital Graphics,170-174. Retrieved from: http://papers.cumincad.org/cgibin/works/paper/sigradi2016_364

Vamvakidis, S. (2019). Computational Design Thinking for first year architectural design studios. In: Sousa, JP, Xavier, JP and Castro Henriques, G (eds.), Architecture in the Age of the 4th Industrial Revolution - Proceedings of the 37th eCAADe and 23rd SIGraDi Conference, 93-98. Retrieved from: http://papers.cumincad.org/cgi-

bin/works/paper/ecaadesigradi2019_043

Van Berkel, B., Bos, C (2006). UNstudio Design Models, New York: Rizzol. 